
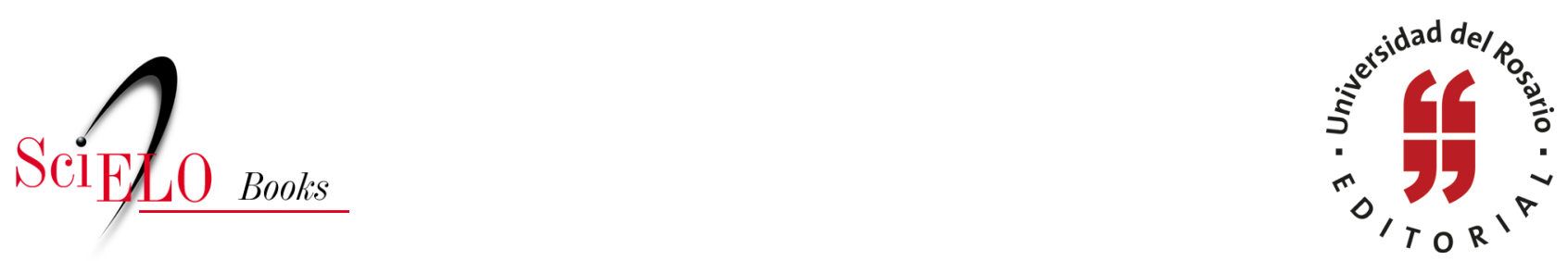

\title{
6. ¿Clientelismo como desviación de la política o como forma de representación?
}

\author{
Laura Daniela Guerrero García
}

\section{SciELO Books / SciELO Livros / SciELO Libros}

GUERRERO GARCÍA, L.D. 6. ¿Clientelismo como desviación de la política o como forma de representación?. In: Clientelismo político, ¿desviación de la política o forma de representación?: Estado del arte sobre las aproximaciones al clientelismo en Colombia 1973-2011 [online]. Bogotá: Editorial Universidad del Rosario, 2014, pp. 79-84. Opera prima collection. ISBN: 978-958-738-552-6. https://doi.org/10.7476/9789587385526.0008.

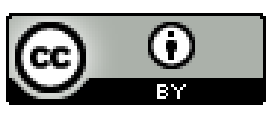

All the contents of this work, except where otherwise noted, is licensed under a Creative Commons Attribution 4.0 International license.

Todo o conteúdo deste trabalho, exceto quando houver ressalva, é publicado sob a licença Creative Commons Atribição 4.0.

Todo el contenido de esta obra, excepto donde se indique lo contrario, está bajo licencia de la licencia $\underline{\text { Creative }}$ Commons Reconocimento 4.0 . 


\section{6. ¿Clientelismo como desviación de la política o como forma de representación?}

Algunos autores discuten que el clientelismo es un fenómeno que se nutre de elementos contradictorios, que en ocasiones chocan entre sí. Sin embargo, es el conjunto de estos elementos opuestos, contradictorios y disímiles, lo que al mismo tiempo facilita sus formas de reproducción. Para Cristina Escobar, el clientelismo "combina asimetría e inequidad con solidaridad, coerción con participación voluntaria, ilegalidad con imágenes públicas de poder y continuidad con inestabilidad". ${ }^{126}$ En esta línea, Javier Fernando Torres atribuye al clientelismo elementos que él denomina virtuosos y, simultáneamente, viciosos.

Paradójicamente, el clientelismo ha contribuido a la ya histórica debilidad estatal, y a su vez ha permitido que el pueblo se sienta "incluido" en el juego político. En esta medida, ha permitido cierta estabilidad y funcionamiento a las instituciones, aunque no de la manera adecuada. El clientelismo ha sido un mecanismo perverso, por lo que significa en términos de debilitamiento de las instituciones democráticas, pero útil como eje de la política regional y local. ${ }^{127}$

${ }^{126}$ Ver Escobar, Clientelism, 37.

${ }^{127}$ Ver Torres Preciado, “Vicio”, 107. 
La existencia de dichos elementos ha conducido a que los estudios sobre clientelismo oscilen en dos grandes tendencias o aproximaciones. A un extremo del espectro se encuentran los autores que atribuyen al clientelismo y a las redes patrón-cliente un carácter moralmente indeseable o "malévolo", con consecuencias negativas para el sistema político inexploradas. ${ }^{128} \mathrm{Al}$ otro extremo, están quienes hacen hincapié en aspectos "positivos" del clientelismo, argumentando que este es un canal de distribución y de movilidad social, un mecanismo de representación política y de construcción de una res pública ${ }^{129}$, al igual que una fuerza estabilizadora entre partidos. ${ }^{130}$

\subsection{Clientelismo como desviación}

En Colombia,los estudios sobre clientelismo político se han inclinado más por observarlo en clave negativa, desde enfoques como el institucionalista y el marxista, predominantes en los años setenta y ochenta. Para los institucionalistas, el clientelismo está fuertemente ligado a la corrupción, el debilitamiento de la institucionalidad y el detrimento del ejercicio democrático. Para los marxistas, el clientelismo se observa como un mecanismo de instrumentalización

${ }^{128}$ Comparar también Roll, Rojo; García Villegas y Revelo Rebolledo, Estado; Luis Hernández Humberto, “Colombia: Mafia y sistema político”, en $\dot{\zeta}$ Estado y cultura mafiosa en Colombia?, ed. Óscar Mejía Quintana, (Bogotá: Universidad Nacional de Colombia, Facultad de Derecho, Ciencias Políticas y Sociales, Instituto Unidad de Investigaciones Jurídico-Sociales Gerardo Molina, 2010), 127-147.

${ }^{129}$ La Res Pública es una expresión del latín que denota la cosa pública.

${ }^{130}$ Comparar también Archer, The Transition, 4-5; Dávila Ladrón de Guevara, “Clientelismo, intermediación”, 62-78; García Sánchez, "La política”; García Sánchez, ¿̇iudadanía avergonzada?; Francisco Gutiérrez Sanín, "Historia de democratización anómala: el partido Liberal en el sistema político colombiano desde el Frente Nacional hasta hoy", en Degradación o cambio: evolución del sistema político colombiano, comp. Francisco Gutiérrez Sanín (Bogotá: Editorial Norma, 2002), 25-78; Rubio Serrano, No hay paraísos. 
del ser humano. Entre los institucionalistas que observan al clientelismo en clave negativa se puede citar a David Roll, Mauricio García y Javier Revelo. Roll asegura que:

El clientelismo es una especie de corrupción a tres bandas, pues al mismo tiempo que afecta negativamente los bienes y servicios públicos, al feriarlos, perjudica un bien no patrimonial del Estado -la representación-,y por añadidura contribuye a generar una cultura de la corrupción, la cual se expresa en actos diferentes pero inspirados en el mismo anti principio de la preeminencia del interés particular sobre el colectivo. ${ }^{131}$

García y Revelo, por su parte, aseguran que dentro de la institucionalidad colombiana hay un clima proclive a ver el clientelismo como norma superior debido a la función distributiva que cumple. ${ }^{132}$ A pesar de eso, la asociación entre corrupción y clientelismo hace que la atribución de prácticas clientelistas a políticos genere inmediatamente el detrimento de su imagen y de su buen nombre. En este orden, la Constitución de 1991 y la reforma electoral de 2003 tenían como objetivo dar muerte al fenómeno del clientelismo; pero, como se ha visto, estas producen su adaptación y no eliminación. Andrés Dávila replica que la cercanía del clientelismo con la corrupción administrativa y fiscal generó un clima propicio para asociarlo con la corrupción política. A pesar de tratarse de fenómenos diferentes, es evidente que quienes intercambian los bienes deben darle un tratamiento deferencial

${ }^{131}$ Ver Roll, “El clientelismo”, 115.

${ }^{132}$ Comparar García Villegas y Revelo Rebolledo, Estado, 31. 
a las reglas en cada caso, originando una frontera entre lo legal y lo ilegal que crea la antesala para la corrupción política. ${ }^{133}$

Para quienes asocian el clientelismo con corrupción política, el fenómeno se convierte en el primer factor que vulnera las bases del sistema democrático y fragmenta la igualdad de los ciudadanos por favorecer privilegiadamente a unos pocos a partir de la repartición desproporcional e inequitativa del erario público. ${ }^{134}$ Sin embargo, para superar las dificultades analíticas, es necesario establecer los límites entre la corrupción y el clientelismo y evitar estas apresuradas asimilaciones. El clientelismo que se da desde las instituciones públicas se genera a partir de la manipulación de las estructuras formales para el beneficio de grupos o sectores particulares. Por el contrario, la corrupción implica una trasgresión directa de las normas. ${ }^{135}$ Estos presupuestos nos obligan a hacernos las siguientes preguntas: ¿Qué sucede cuando se crean leyes para prevenir formas particulares de hacer política? ¿Es acaso desde este instante en que el clientelismo deviene en corrupción?

El reto que tienen los nuevos estudios sobre clientelismo consiste en superar el grado de ambigüedad del concepto y esto implica, en gran medida, tratar de eliminar todas aquellas interpretaciones que tienden a asociarlo con todos los vicios del sistema político colombiano. Este es un objetivo difícil, pero además peligroso, tal como plantea Francisco Gutiérrez, la noción "apropiación privada de lo público" pareciera ser una categoría aún inexplorada que podría acercarnos aún más a la delimitación, tanto de la corrupción como del clientelismo. Sin embargo, todavía hacen falta trabajos

\footnotetext{
${ }^{133}$ Dávila Ladrón de Guevara, “Clientelismo, intermediación”, 69.

${ }^{134}$ Comparar Roll, "El clientelismo”, 115.

${ }^{135}$ Duarte, Educación, 9.
} 
comparados que nos ayuden a establecer relaciones de causalidad y operacionalización de los fenómenos. ${ }^{136}$

\subsection{Clientelismo como representación}

La constitución de 1991 buscaba la modernización de la política, la apertura democrática y la erradicación del clientelismo. ${ }^{137}$ No obstante, el fenómeno no desapareció con la reforma. La constatación de este hecho generó una revisión del clientelismo en los estudios posteriores a 1991. Desde entonces, la definición y uso del concepto se problematiza, anotando un laxo empleo del mismo como sinónimo de corrupción e ilegalidad. Emergen, por ende, preguntas sobre la naturaleza del fenómeno, sus continuidades y transformaciones.

Ante la trasformación del régimen, O'Donnell, sugiere asumir al clientelismo no como un aspecto que se ubica fuera de la institucionalidad, sino como una forma diferente de la misma u "otra institucionalidad" anclada a los procesos de construcción del Estado y al sistema democrático de cada país. ${ }^{138}$

Al clientelismo, también, se le ha considerado como el mecanismo que superó la violencia sectaria entre liberales y conservadores a partir del Frente Nacional. ${ }^{139}$ Los partidos se convirtieron

${ }^{136}$ Comparar Francisco Gutiérrez Sanín y Andrés Dávila Ladrón de Guevara, "Paleontólogos o politólogos: ¿Qué podemos decir hoy sobre los dinosaurios?”, Revista de Estudios Sociales, (2000): 45.

${ }^{137}$ Algunos de los mecanismos creados por la Constitución de 1991 que castigaban las prácticas de clientelismo electoral eran: la circunscripción nacional para senado, el tarjetón, la no acumulación de mandatos, la modificación del calendario electoral, la desaparición de las suplencias, la pérdida de la investidura, el remplazo de la inmunidad parlamentaria por fuero y aumento drástico de las incompatibilidades.

${ }^{138}$ Comparar Dávila Ladrón de Guevara, “Clientelismo, intermediación”, 65.

${ }^{139}$ Ibid., 67-68. 
en aliados, se puso fin a la violencia política y se facilitó la continuidad de la democracia formal y el del resto de instituciones políticas. ${ }^{140}$

Sin embargo, adicional a estos pequeños elementos que permiten entrever aspectos positivos del clientelismo, autores como Miguel García, Francisco Gutiérrez, Andrés Dávila y Rocío Rubio marcaron un precedente en la forma de abordar el fenómeno al encontrar que las reformas hechas en Bogotá originaron dinámicas en las cuales hay un proceso de negociación, entre clientelas e intermediarios, para tramitar demandas sociales ante el Estado, generando un proceso de participación ciudadana que no necesariamente es ajeno a la democracia.

${ }^{140}$ Comparar también Ricardo Peñaranda y Javier Guerrero (compiladores), De las armas a la politica (Bogotá: TM Editores; IEPRI, 1999). 